\title{
Unprecedented coring performance with the upgraded Research Vessel Marion Dufresne
}

\author{
Aline Govin', N. Vázquez Riveiros' ${ }^{1}$, Y. Réaud ${ }^{2}$, C. Waelbroeck ${ }^{1}$ and J. Giraudeau ${ }^{3}$
}

\begin{abstract}
The MD203 ACCLIMATE expedition was the first coring cruise onboard the Research Vessel Marion Dufresne since her midlife refit in 2015 (Rousseau et al. 2016). Taking place in March 2016 in the South Atlantic Roaring Forties and Howling Fifties, this cruise provided a full-scale exercise to test, in rough sea conditions, the latest generation of sediment coring equipment.
\end{abstract}

To illustrate the unprecedented quality of long sediment sequences taken with the improved giant CALYPSO piston corer, we compared two deep-water cores collected $\sim 13 \mathrm{~km}$ apart on the South African margin (Fig. 1): (1) core MD02-2587 taken in 2002 with the former coring facilities and (2) core MD163510 recovered with the new coring facilities.

The similarity of downcore sediment reflectance changes measured on board confirmed that both cores record the same climatic and environmental events (Fig. 1A-C). However, the 2002 core is stretched by up to $30 \%$ compared to the 2016 core, meaning that, for a similar core length, the 2016 core goes further back in time. Also, the 2002 core
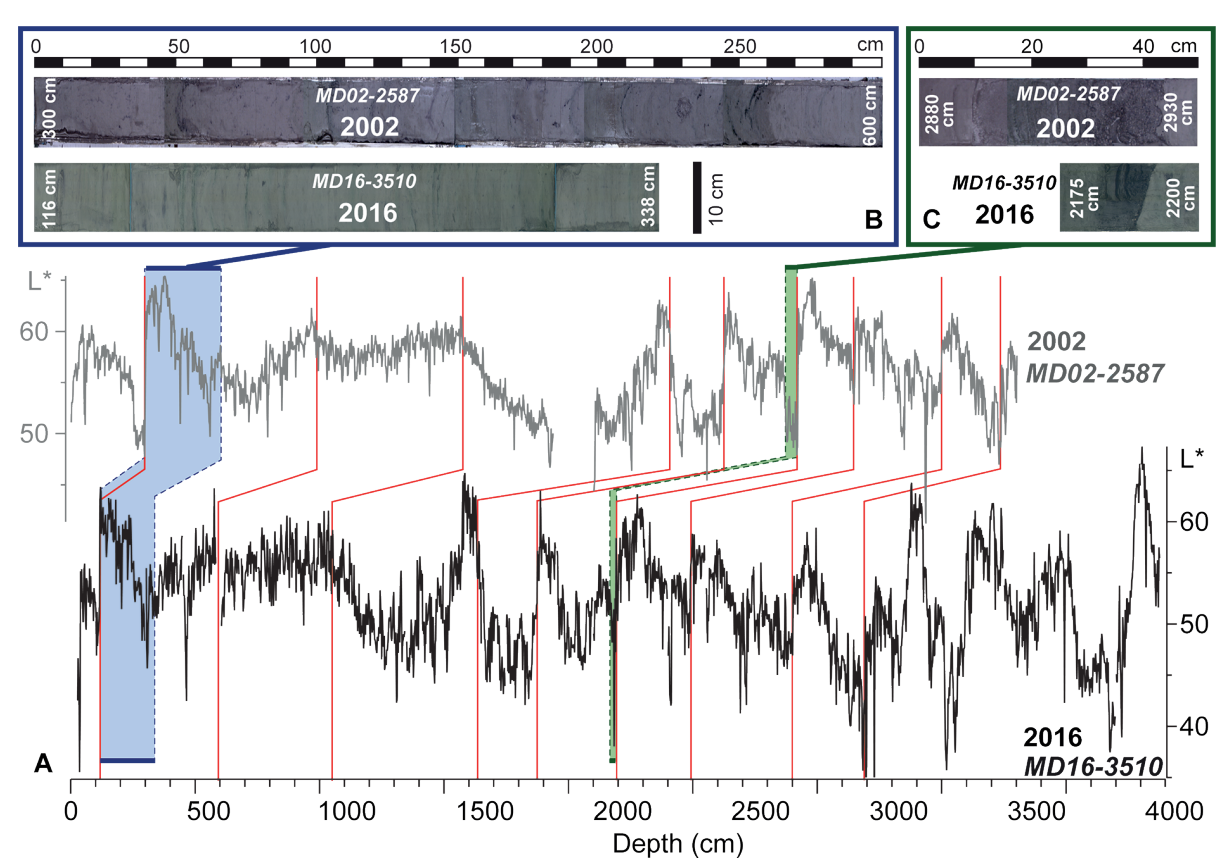

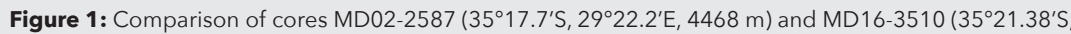
$29^{\circ} 14.78^{\prime} \mathrm{E}, 4435 \mathrm{~m}$ ) collected in 2002 and 2016, respectively, at the same South African margin site. (A) Downcore reflectance $\left(L^{*}\right)$ changes in both cores on their respective depth-scales. Red lines highlight conspicuous color changes synchronous in both cores. The 2002 core is stretched compared to the 2016 core. (B) Core photographs of the same time period (blue area) covered by 300 and $222 \mathrm{~cm}$ of sediments in the 2002 and 2016 cores, respectively. Dark layers are straight in the 2016 core, while bent in the 2012 core. (C) Core photographs of the same turbiditic event (green area). The characteristic downward coarsening of turbiditic sediments is stretched in the 2002 core. These features illustrate the absence of sediment stretching and deformation in the 2016 core, in opposition to the 2002 core. exhibited signs of coring deformation marked by bent dark layers, which, in contrast, are straight in the 2016 core (Fig. 1B). The absence of sediment stretching and defor2016 core thus highlighted the unprecedented quality of this $\sim 45$-meter-long core taken at $\sim 4400 \mathrm{~m}$ of water-depth with a

Sediment stretching and deformation were known features of giant piston cores taken with the former R/V Marion Dufresne coring facilities (Skinner and McCave 2003). They which, after the sudden release of the corer weight, caused the upward acceleration of the piston and hence over-sampling of the

Three major modifications of the R/V Marion Dufresne coring facilities, in addition to the standing quality of sediment cores recovered during the ACCLIMATE cruise. First, the use of a specially designed DYNEEMA synthetic cable, with a controlled minimum elasticity, strongly limited the elastic rebound of the

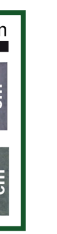

L

'Laboratoire des Sciences du Climat et de l'Envi-

ronnement, Université Paris Saclay, Gif sur Yvette, France

${ }^{2}$ National Centre for Drilling and Coring, Centre

National de la Recherche Scientifique, Brest, France ${ }^{3}$ Environnements et Paléoenvironnements Océaniques et Continentaux, Université de Bordeaux, Pessac, France

CONTACT

Aline Govin: aline.govin@|sce.ipsl.fr

LINKS

http://climcor-equipex.dt.insu.cnrs.fr/

http://www.sea.acclimateproject.eu/

REFERENCES

Bourillet J-F et al. (2007) 6th international conference on Offshore Site Investigation and Geotechnics: Confronting New Challenges and Sharing Knowledge. Society of Underwater Technology, London, UK

Rousseau D-D et al. (2016) PAGES Mag 24: 26 Skinner LC, McCave IN (2003) Mar Geol 199: 181-204 Woerther P et al. (2012) Improving in piston coring quality with acceleration and pressure measurements and new insights on quality of the recovery, INMARTECH 2012, Texel, the Netherlands 